\title{
Midwest Micrometeorites
}

Scott Peterson ${ }^{1}$, Anette von der Handt ${ }^{2}$

${ }^{1 .}$ Minneapolis, USA.

2. University of Minnesota, Department of Earth Sciences, Minneapolis, USA.

Micrometeorites collected on urban rooftops are gaining rapid interest as a field of study. Micrometeorites are extraterrestrial particles that have been previously found in deep-sea sediments as well as deserts and Antarctica (e.g. 1,2) but can also be found in urban environments. They range in size between $0.2 \mathrm{~mm}-0.4 \mathrm{~mm}$ but are able to get as small as $0.075 \mathrm{~mm}$ in size. They often are spherical but can also exhibit elongated shapes caused by spin during atmospheric entry. Most micrometeorites show a characteristic assemblage of silicate minerals, some with high Nickel-bearing metal inclusions commonly also found in meteorites. Project Stardust (https://www.facebook.com/micrometeorites/) is the largest source of information on urban micrometeorites on the web and is headed by Jon Larsen (University of Oslo, Department of Geosciences) who mentored this effort.

Sampling sites are flat roofs within the wider Minneapolis/St. Paul area, but will soon include Wisconsin and North Dakota as well. Rooftops older than 10 years old have been found to be very promising but at a rate of one micrometeorite per square meter per year any roof has a possibility of being suitable. Collection methods include using a powerful neodymium magnet wrapped tightly in a small zip lock bag and samples then collected in a separate bag. The material is then cleaned with hot water and sieved for the desirable size range $(0.2-0.4 \mathrm{~mm})$. Once the material is thoroughly cleaned, it is studied under the microscope and promising candidates set aside for further analysis. While micrometeorites can be easily confused with metallic particulates and other particles from modern pollution (e.g. particles caused by machinery such as grinding wheels), they can be identified with great likelihood based on physical characteristics alone (Figure 1) with some experience.

Samples are then further studied by electron microprobe (JEOL JXA-8900R and JEOL JXA-8530FPlus) at the Department of Earth Sciences at the University of Minnesota. At this point, it is possible to verify any unknown particles as micrometeorites through chemical analysis.

This represents one of few systematic urban micrometeorite collections in the world and the first in the United States. To date, the collection contains $\sim 40$ micrometeorite. Of these, 27 are Barred Olivine, 6 are cryptocrystalline, 3 are Porphyritic, and 2 are Glassy based on their microscopic texture and chemical composition. Through continued sampling and further study, this collection is rapidly expanding and we will provide an overview of Midwest micrometeorites.

References:

[1] M.B. Blanchard et al., EPSL 46 (1980), p. 178-190.

[2] P. Rochette, et al., PNAS 105 (2008) p. 18206-18211; DOI: 10.1073/pnas.0806049105 


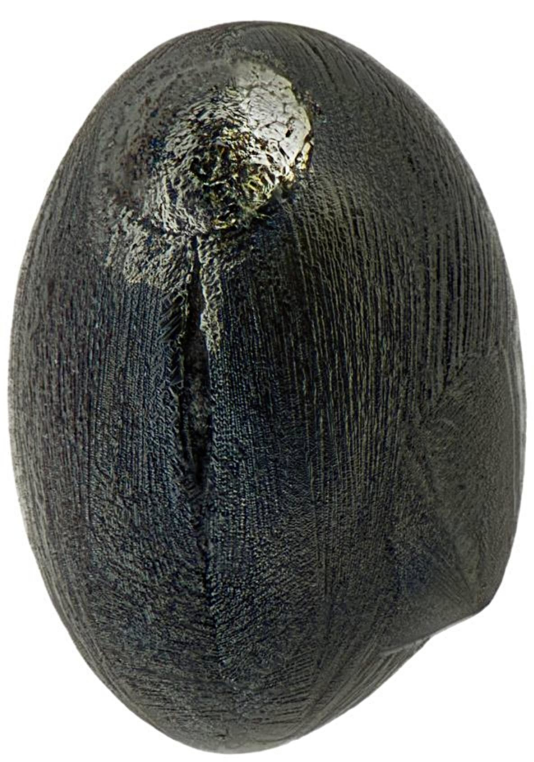

Figure 1. Microscope image of one micrometeorite. They often contain metal beads at one end of the elongated particle as shown by this specimen.

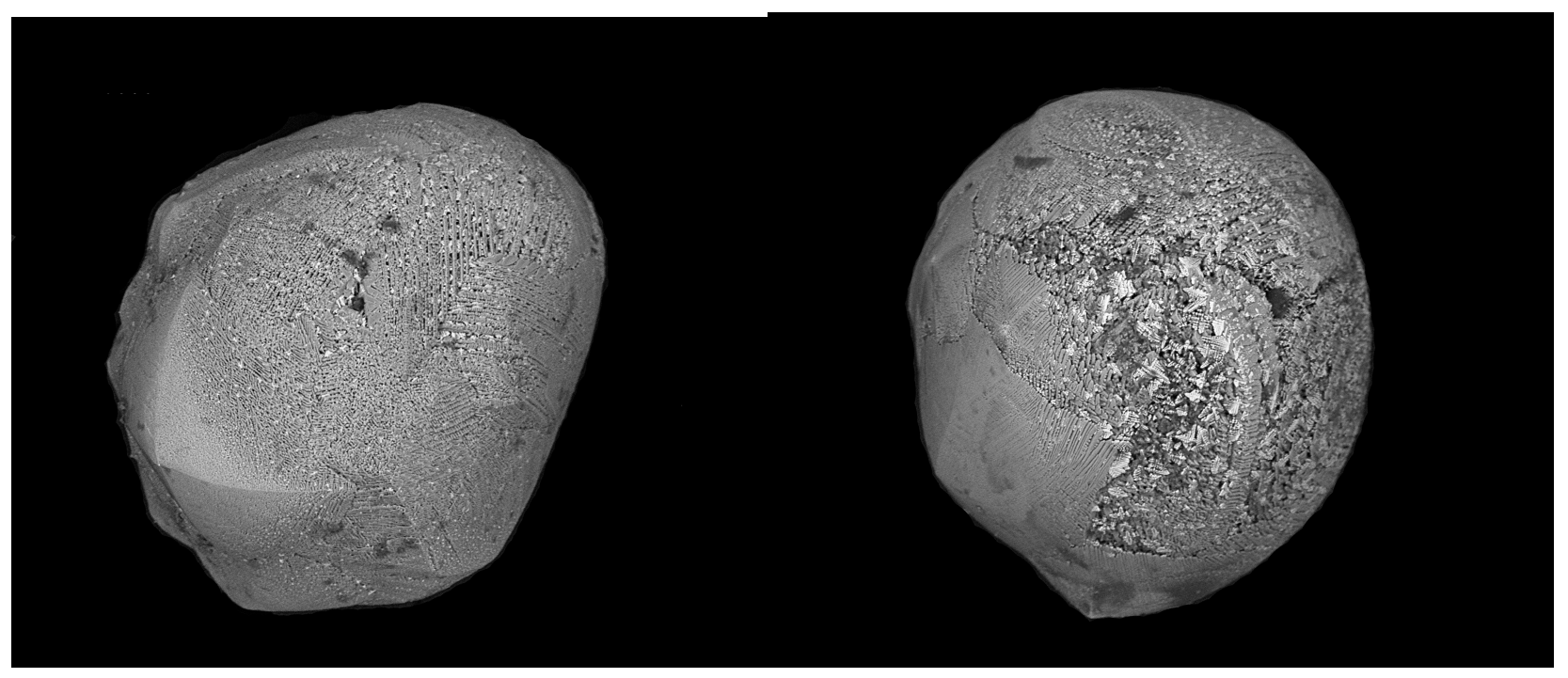

Figure 2. Backscattered electron images of two micrometeorites, showing radiating clusters of olivine dendrites and metal inclusions. 